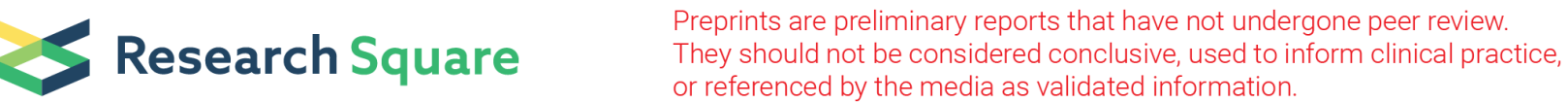

\section{Implementation of An Intravitreal Therapy Online Audit Tool For Neovascular Age-related Macular Degeneration Clinical Outcomes Reporting: Fight Retinal Blindness Spain (FRB-Spain) Project}

\author{
Alba Parrado-Carrillo \\ Institut Clínic d’Oftalmologia (ICOF), Hospital Clínic \\ Marc Figueras-Roca \\ Institut Clínic d’Oftalmologia (ICOF), Hospital Clínic \\ Ricardo P. Casaroli-Marano \\ Institut Clínic d'Oftalmologia (ICOF), Hospital Clínic \\ Vuong Nguyen \\ University of Sydney, Save Sight Institute \\ Daniel Barthelmes \\ University of Zurich \\ Mark C. Gillies \\ University of Sydney, Save Sight Institute \\ Javier Zarranz-Ventura ( $\boldsymbol{D}$ jzarranz@hotmail.com ) \\ Institut Clínic d’Oftalmologia (ICOF), Hospital Clínic
}

\section{Research Article}

Keywords: Implementation, audit, benchmark standard, ranibizumab, aflibercept, bevacizumab, neovascular AMD, Age-related Macular degeneration, anti-VEGF

Posted Date: July 30th, 2021

DOl: https://doi.org/10.21203/rs.3.rs-728652/v1

License: (9) This work is licensed under a Creative Commons Attribution 4.0 International License. Read Full License 


\section{Abstract}

Purpose: To implement an intravitreal therapy audit tool for neovascular age-related macular degeneration (nAMD) outcome reporting in a tertiary referral center.

Methods: Implementation of an online audit tool (Fight Retinal Blindness platform) for nAMD eyes receiving anti-vascular endothelial growth factor (anti-VEGF) intravitreal therapy over a 24-month followup period. Data entry was compliant with the ICHOM dataset for nAMD. These data included visual acuity (VA), eye conditions, injection drug and number of injections. Subgroup analysis was performed for treatment-naive (TN) and previously treated (PT) eyes.

Results: 234 eyes (191 patients) were included in the study. No significant differences were observed in the subgroup analysis in mean baseline VA (logMAR letters: 58.8 TN vs 62.7 PT, $p=0.081$ ) or final VA at 12 months (TN 61.4 vs PT 62.4; $p=0.703$ ). However, 12 months median VA change favoured TN cases (+4 TN vs +0 PT, $p=0.010$ ) and median number of injections showed no differences (7 TN vs 7 PT, $p=$ $0.644)$. No statistically significant differences were found at two years on number of injections even though mean final VA showed significant differences (66 TN vs $59.5 \mathrm{PT}, \mathrm{p}=0.032$ ) and VA change favoured the TN group (+2.4 TN vs - 4.6 PT, $p=0.003)$.

Conclusion: We have successfully implemented an online tool to evaluate nAMD anti-VEGF treatment delivered in our center. This feasibility study demonstrates that the online audit tool allows evaluating real world intravitreal therapy outcomes and benchmark these results with clinical practice guidelines and other real-life series.

\section{Introduction}

Pivotal clinical trials have demonstrated the efficacy of drugs against vascular endothelial growth factor (VEGF) in neovascular age-related macular degeneration (nAMD) using fixed dosage treatment regimens $^{1-2}$. These studies determine whether new treatments are effective in a highly selected group of patients that may not be representative of the general population (internal validity comes at cost of external validity of its results). Moreover, current trends in clinical practice tend to individualize treatment protocols, such as treat and extend approaches $(\mathrm{TAE})^{3}$. Large-scale population-based observational studies therefore represent a different level of evidence that can complement findings from clinical trials and determine treatment effects in routine clinical practice, with higher external validity. Such real-world studies track patients for longer periods of time and can provide enriching results on safety, quality of life, long-term effectiveness and can identify significant drug adverse events that were not detected in clinical trials ${ }^{4}$.

The Fight Retinal Blindness (FRB) online platform is a web-based data collection tool designed and developed at Save Sight Institute (Australia) to track clinical outcomes in routine clinical practice, with several modules including retinal diseases as nAMD or diabetic retinopathy, but also glaucoma and 
corneal diseases ${ }^{5}$. Data collection for the nAMD module includes visual acuity (VA), ocular characteristics, drug types, number of injections and lesion activity at baseline and at each follow-up visit. This structured data entry system allows the collection of accurate, systematic and high-quality clinical data that enable physicians to self-audit their clinical outcomes. This ability to evaluate individual centre results allows clinicians to benchmark their real-life results with pivotal clinical trials, to compare different drugs or treatment protocols, as well as to determine long-term safety of anti-VEGF therapies in unselected eyes outside a clinical trial scenario ${ }^{6-9}$. Deployed in a multicentre approach, this tool collates a large series of eyes in order to identify predictive factors of treatment response, as per recent publications ${ }^{10}$. Australia, New Zealand and Switzerland have been tracking their outcomes with this system since 2007, and as January 2019 the FRB registry included data from approximately 184.562 treatments from about 12.949 eyes of 10.100 patients with nAMD.

The opportunity to implement audit tools such as the FRB online platform appears specially interesting in countries like Spain, where few data about real-life outcomes of anti-VEGF drugs for nAMD have been previously reported. With this aim, we established a pilot study to evaluate the feasibility of performing a real-world clinical care audit using the FRB platform, to ascertain the outcomes of a single intravitreal therapy unit in a tertiary referral public centre of Barcelona.

\section{Methods}

\section{Design and Setting}

Observational study of data collected from eyes that commenced intravitreal therapy for nAMD and had been tracked in the FRB platform. The details of the FRB database have been already published ${ }^{5}$. Briefly, collected data from each clinical visit included VA measured as a number of letters read on a logarithm of the minimum angle of resolution (logMAR), other ocular conditions (i.e. pseudophakia), fluorescein angiography characteristics of the lesion, activity of the choroidal neovascular membrane, given treatment, and presence of ocular adverse events. The local Ethics Committee approved this study for Clinical Research (UASP, Hospital Clinic de Barcelona, Barcelona, Spain; HCB/2018/0123) The research described adhered to the tenets of the Declaration of Helsinki and written informed consent was obtained from each enrolled participant. The processing, communication and transfer of personal data of all subjects comply with the provisions of European Data Protection Regulation EU 2016/679 and local law (RD 5/2018) regarding clinical data protection.

\section{Patient Selection and Variables}

Patients included in the analysis consisted of eyes initiating intravitreal therapy from March 2015 to January 2018 with either ranibizumab or aflibercept for nAMD treatment that had completed 12 or 24 months of follow-up. Treatment-naive eyes were included as well as previously treated ones. Given treatment approaches mainly included Treat and Extend (TAE) strategies as well as fixed bimonthly injections regimes ${ }^{8,11}$. Lesions were graded as "active" if presenting with sub- and intra-retinal fluid at the 
optical coherence tomography (OCT) examination or new haemorrhage at dilated fundus exploration, "active-subretinal fluid" if only subretinal fluid was present or "inactive" if no changes of activity were observed by physician examination.

\section{Outcomes}

The main outcomes were final VA, change in VA and number of injections and visits during follow-up. In addition, eyes were considered in two groups depending on prior treatment received [treatment-naive (TN) vs previously treated (PT)]. For each group of eyes, the mean baseline VA and mean final VA, as well as the proportions of eyes with VA of $>70$ letters (20/40 Snellen) and $<35$ letters (20/200 Snellen) were obtained at 12 and 24 months. Median number of injections and visits were also reported at the same time points.

\section{Statistical Analysis}

Absolute frequencies and percentages (\%) were used to describe categorical variables as well as overall number of eyes in each group. Description of quantitative variables was performed with mean and standard deviation (SD), median and interquartile intervals (Q1;Q3), and 95\% confidence interval (Cl) where appropriate. Student T, Wilcoxon rank-sum, ANOVA, Kruskal-Wallis, McNemars, Fishers and chisquare tests were used as appropriate to compare baseline characteristics between site groups for 12and 24-month completers. A bilateral type I error of $5 \%$ was established. All analyses were performed using $\mathrm{R}$ version 3.3.1.

\section{Results}

Data from a total number of 234 eyes (191 patients) with nAMD was collected in the FRB online platform, corresponding to more than 100.000 data fields, VA measurements from 2.815 outpatient visits and more than 2.114 treatment episodes.

The demographic characteristics of study population are detailed in Table 1. At baseline, mean age was 82 years, $59.7 \%$ were female and mean VA was 59.7 logMAR letters. Considering previous treatment status, $54.27 \%$ were TN and $45.73 \%$ were PT. During the study follow-up, the majority of patients were kept on a TAE strategy (69.8\%). Regarding anti-VEGF drugs distribution, aflibercept was predominantly used in both groups (83.6\% TN, 59.7\% PT) as well as ranibizumab (16.4\% TN, 40.3\% PT). 
Table 1

Demographic information for all eligible patients, with p-values comparing pre-treated vs. treatment-naïve eyes.

\begin{tabular}{|lllll|}
\hline & All Eyes & Pre-treated & Treatment-naïve & p-value \\
\hline Eyes & 234 & 107 & 127 & \\
\hline Patients & 191 & 91 & 110 & 0.857 \\
\hline Females, \% patients & $59.7 \%$ & $60.4 \%$ & $58.2 \%$ & 0.681 \\
\hline Age, mean (SD) & $81.4(7.1)$ & $81.6(6.5)$ & $81.2(7.7)$ & 0.039 \\
\hline Baseline VA & & & 0.037 \\
\hline Mean (SD) & $59.7(17.7)$ & $62.3(16.5)$ & $57.5(18.4)$ & 0.257 \\
\hline Median (Q1, Q3) & $65(50,74)$ & $66(53,75)$ & $65(50,70)$ & 0.034 \\
\hline$\leq 35$ Letters, n (\%) & $34(14,5 \%)$ & $12(11.2 \%)$ & $22(17.3 \%)$ & $41(32.3 \%)$ \\
\hline$\geq 70$ Letters, n (\%) & $91(38.9 \%)$ & $50(46.7 \%)$ & & \\
\hline $\begin{array}{l}\text { Abbreviations: Q1 = first quartile (25th percentile); Q3 = third quartile (75th percentile); SD = standard } \\
\text { deviation; VA = visual acuity in logMAR letters }\end{array}$ & & & \\
\hline
\end{tabular}

Table 2 summarizes visual outcomes at 12 months comparing TN vs PT eyes consisting in 114 TN and 101 PT eyes, with no difference in mean baseline VA between two groups (TN 58.8 vs PT 62.7; $p=0.081$ ). No statistical differences were found in final VA (TN 61.4 vs PT 62.4; $p=0.703)$ even though a significant difference in VA change favoured TN cases (median gain of +4.0 letters in TN compared to +0 in PT; $p=$ $0.010)$. A VA $>70$ letters ( $>20 / 40$ ) was found in $34.2 \%$ of TN eyes vs $46.5 \%$ of PT eyes at the initial visit and in $48.2 \%$ vs $46.5 \%$ at 12 months. Regarding the number of injections during the first year, both groups showed a median of 7 injections (Q1Q3 6;8 $p=0.644)$. The median number of visits was only slightly greater in the TN group with TN 9 (Q1Q3 7;9) vs PT 7 (Q1Q3 6;8); $p<0.001)$. 
Table 2

Visual outcomes at 12 months for all eligible eyes, treatment-naïve and pre-treated eyes P-values are comparing pre-treated and treatment-naïve eyes.

\begin{tabular}{|c|c|c|c|c|}
\hline & All eyes & Pre-treated & Treatment-naïve & P-value \\
\hline Completers & $215(91.9 \%)$ & $101(94.4 \%)$ & $114(89.8 \%)$ & \\
\hline \multicolumn{5}{|l|}{ Baseline VA } \\
\hline Mean (SD) & $60.6(16.6)$ & $62.7(16.1)$ & $58.8(16.9)$ & 0.081 \\
\hline Median (Q1, Q3) & $65(51,74)$ & $66(53,75)$ & $65(50,70.8)$ & 0.067 \\
\hline \multicolumn{5}{|l|}{ Final VA } \\
\hline Mean (SD) & $61.9(18.8)$ & $62.4(17.5)$ & $61.4(19.9)$ & 0.703 \\
\hline Median (Q1, Q3) & $68(53,75)$ & $67(53,75)$ & $69(53,75)$ & 0.940 \\
\hline VA $\leq 35, \%$ baseline / $\%$ final & $12.6 \% / 12.6 \%$ & $9.9 \% / 10.9 \%$ & $14.9 \% / 14 \%$ & \\
\hline$V A \geq 70, \%$ baseline / $\%$ final & $40 \% / 47.4 \%$ & $46.5 \% / 46.5 \%$ & $34.2 \% / 48.2 \%$ & \\
\hline \multicolumn{5}{|l|}{ VA change } \\
\hline Mean $(95 \% \mathrm{Cl})$ & $1.2(-0.6,3.1)$ & $-0.3(-2.4,1.7)$ & $2.6(-0.3,5.6)$ & 0.103 \\
\hline Median (Q1, Q3) & $1(-4,8)$ & $0(-5,5)$ & $4(-3.8,11.8)$ & 0.010 \\
\hline \multicolumn{5}{|l|}{ VA change, $\%$ loss / $\%$ gain } \\
\hline$\geq 5$ letters & $24.2 \% / 39.5 \%$ & $25.7 \% / 28.7 \%$ & $22.8 \% / 49.1 \%$ & \\
\hline$\geq 10$ letters & $14.4 \% / 23.3 \%$ & $11.9 \% / 12.9 \%$ & $16.7 \% / 32.5 \%$ & \\
\hline$\geq 15$ letters & $11.2 \% / 13.5 \%$ & $8.9 \% / 5.9 \%$ & $13.2 \% / 20.2 \%$ & \\
\hline Injections, median (Q1, Q3) & $7(6,8)$ & $7(6,8)$ & $7(6,8)$ & 0.644 \\
\hline Ranibizumab\%/Aflibercept \% & $27.5 / 72.5$ & $40.3 / 59.7$ & $16.4 / 83.6$ & \\
\hline Visits, median (Q1, Q3) & $8(7,9)$ & $7(6,8)$ & $9(7,9)$ & $<0.001$ \\
\hline
\end{tabular}

Table 3 reports visual outcomes at 24 months, with a total of 67 TN and 82 PT completers. Outcomes show no differences in mean baseline VA (63.6 TN, 64.1 PT, $p=0.844)$ but TN cases perform with higher final VA ( $66 \mathrm{TN}, 59.5 \mathrm{PT}, \mathrm{p}=0.032$ ). VA change at 24 months favoured the TN group, showing a gain of 2.4 letters in TN vs a loss of 4.6 in PT (p: 0.003) (Fig. 1). At 24 months, there weren't differences in median number of injections: TN 11 (Q1Q3 10;14) vs PT 12 (Q1Q3 10;13), $p=0.554$. No differences were found in the median number of visits with 13 TN (Q1Q3 11;14) vs 14 PT (Q1Q3 13;16); $p=0.094)$. 
Table 3

Visual outcomes at 24 months for all eligible eyes, treatment-naïve and pre-treated eyes P-values are comparing pre-treated and treatment-naïve eyes.

\begin{tabular}{|c|c|c|c|c|}
\hline & All eyes & Pre-treated & Treatment-naïve & P-value \\
\hline Completers & $149(63.7 \%)$ & $82(76.6 \%)$ & $67(52.8 \%)$ & \\
\hline \multicolumn{5}{|l|}{ Baseline VA } \\
\hline Mean (SD) & $63.9(14.7)$ & $64.1(15.4)$ & $63.6(14)$ & 0.844 \\
\hline Median (Q1, Q3) & $66(57,75)$ & $67(55.5,76.8)$ & $65(57,75)$ & 0.649 \\
\hline \multicolumn{5}{|l|}{ Final VA } \\
\hline Mean (SD) & $62.4(19)$ & $59.5(20.7)$ & $66(16.1)$ & 0.032 \\
\hline Median (Q1, Q3) & $69(53,77)$ & $67(47.5,73)$ & $70(58,77)$ & 0.037 \\
\hline VA $\leq 35, \%$ baseline / \% final & $7.4 \% / 14.1 \%$ & $8.5 \% / 18.3 \%$ & $6 \% / 9 \%$ & \\
\hline VA $\geq 70, \%$ baseline / \% final & $47.7 \% / 48.3 \%$ & $47.6 \% / 39 \%$ & $47.8 \% / 59.7 \%$ & \\
\hline \multicolumn{5}{|l|}{ VA change } \\
\hline Mean $(95 \% \mathrm{Cl})$ & $-1.4(-3.8,0.9)$ & $-4.6(-7.6,-1.6)$ & $2.4(-1.2,6)$ & 0.003 \\
\hline Median (Q1, Q3) & $0(-6,6)$ & $-2(-9.5,2)$ & $5(-3,10)$ & $<0.001$ \\
\hline \multicolumn{5}{|l|}{ VA change, $\%$ loss / $\%$ gain } \\
\hline$\geq 5$ letters & $31.5 \% / 34.2 \%$ & $39 \% / 20.7 \%$ & $22.4 \% / 50.7 \%$ & \\
\hline$\geq 10$ letters & $20.8 \% / 17.4 \%$ & $25.6 \% / 9.8 \%$ & $14.9 \% / 26.9 \%$ & \\
\hline$\geq 15$ letters & $14.8 \% / 10.1 \%$ & $18.3 \% / 3.7 \%$ & $10.4 \% / 17.9 \%$ & \\
\hline Injections, median (Q1, Q3) & $11(10,13)$ & $11(10,14)$ & $12(10,13)$ & 0.554 \\
\hline Ranibizumab\%/Aflibercept \% & $27 / 73$ & 33.9 / 66.1 & 18.4 / 81.6 & \\
\hline Visits, median (Q1, Q3) & $14(12,15)$ & $13(11,14)$ & $14(13,16)$ & 0.094 \\
\hline
\end{tabular}

\section{Discussion}

This study reports the successful implementation of the FRB platform in the intravitreal therapy unit of a single tertiary referral centre, an online audit tool that allowed structured data collection and provided long-term outcomes of a real-world cohort of patients receiving VEGF inhibitors for nAMD. This system enabled the efficient capture of high-quality data, allowing us to benchmark our real-life clinical results and compare them with those reported in randomized clinical trials ${ }^{5}$. 
Real world studies on large-scale population-based data and phase IV studies, which are carried out after regulatory approval is given, are becoming increasingly important nowadays. They track patients for longer and ensure that results obtained in clinical trials extend to the general population, evaluating endpoints as long-term efficacy, safety, quality of life and cost-effectiveness. This is especially important in anti-VEGF therapies because they are usually long-term treatments and nAMD causes a strong negative impact on quality of life $\mathrm{e}^{11-12}$.

Anti-VEGF drugs represent a large proportion of the health system expenditure all around Europe ${ }^{13}$. Previous reports analysing nAMD patients management with intravitreal anti-VEGF in routine clinical practice in our country concluded that this was highly variable between different centres and distant from recommended European guidelines ${ }^{14}$. New technologies give us the opportunity to enhance self-auditing practice in Spain and re-evaluate outcomes, to broaden our knowledge and to optimize the management of our patients. Nonetheless, this could be considered of great importance given the paucity of such information in southern Europe countries, which may socially and economically differ from its northern neighbours.

The results observed in our series present similarities and differences with other real world study cohorts. As expected, we found a higher prevalence of nAMD in women, with a 1.6:1 female-to-male ratio, in line with previously published studies ${ }^{15}$. However, the baseline VA was substantially better in our cohort than other real-world studies (59.7 vs 55-56 logMAR letters) ${ }^{12,16}$ Usually, patients with better baseline VA have a better prognosis and tend to maintain VA in time ${ }^{11}$, but can also present with less room for improvement (ceiling effect) as per VA change. No patient was excluded according to pre-treatment status (as done in most reports ${ }^{8-10}$ ) but a sub-analysis was made according to these criteria. Mean final VA was $61.9 \log M A R$ letters at 12 months and 62.4 at 24 months, with significant differences between TN and PT eyes at 24 months ( $66 \mathrm{TN}, 59.5 \mathrm{PT}, \mathrm{p}=0.032$ ). VA change favoured TN eyes at 12 and 24 months, with gain of +4.0 and +2.4 letters respectively $(p=0.01 ; 0.003)$. These results are comparable to other international cohorts described using FRB platform, such as the Australian ${ }^{12}$, including 1198 eyes under TAE regimen only in which mean VA increased from 56.5 logMAR letters at baseline to 61.8 at 24 months. In the UK, a real-wold multicentre study was performed to study the outcomes of ranibizumab under a PRN approach, obtaining poor results: a total of 12951 eyes with baseline VA 55 logMAR letters and VA gain of -2.0 letters at 24 months ${ }^{17}$. More recently, another UK group reported results using a fixed bimonthly aflibercept treatment regime that achieved better outcomes: 1180 eyes with baseline VA 56.3 logMAR letters and VA gain of +2.3 letters at 24 months $^{18}$. The differences observed between TN and PT eyes in our study cohort, with greater VA gains at 12 and 24 months in the TN group, could be explained by the natural history of the disease after anti-VEGF treatment: initial VA improvement that usually peaks after the loading dose, then stabilizes for a variable period, and gradually decreases over time. ${ }^{19}$

Regarding treatment frequency, no significant differences were observed in the number of injections at 12 months ( 7 vs 7 ) or 24 months (11 vs 12) between both study subgroups. These results are similar to the outcomes reported in randomised clinical trials such as CATT, with a total of 7 injections of ranibizumab 
in the first year ${ }^{20}$, and comparable to other real-world outcomes such us UK cohort with median number of injections of 11.3 of aflibercept at 24 months $^{18}$. At 12 months, number of visits did not substantially differ: TN had slightly greater median number of visits (TN 9 vs PT $7 ; p<0.001$ ), but no differences were observed at 24 months (TN 14 vs PT 13; $p=0.094$ ). This fact could maybe be explained by the administration of monthly loading dose in TN patients. These results are similar to other cohorts previously described using FRB platform like Arnold et al. with a mean number of visits of 7.9 in the first year and 14.6 at 24 months $^{21}$.

This study has several strengths and limitations. Using the FRB database allowed a detailed analysis of nAMD patients treated in routine clinical practice, reflecting real-world utilisation of both anti-VEGF drugs

for the treatment of nAMD. Furthermore, different treatment regimens such as fixed bimonthly dosing and TAE were included, being selected at the discretion of the treating physician ${ }^{21}$. Like all observational studies, it has low internal validity, but it is still meaningful, because this is how clinical practice is actually delivered and reflect routine clinical care. Also, results from long-term observational studies may be affected by external factors, for example, loss of follow-up.

\section{Conclusions}

In conclusion, online platforms such as FRB enhance self-audit practices and facilitate rapid analysis of intravitreal therapy units results, allowing comparisons with other national and international cohorts. The results reported in this study support the use of these systems for auditing purposes in centers transitioning from paper notes to computer systems or unstructured EMR softwares. Further research is warranted with larger cohorts and longer follow-up to determine whether the positive results herein reported are sustained over time.

\section{Abbreviations}

Cl: Confidence interval

CRT: Central retinal thickness

FRB: Fight Retinal Blindness

ICHOM: International Consortium for Health Outcome Measurement

IQR: Interquartile range

IRB: Institutional review board

LogMAR: logarithm of the mínimum angle of resolution

nAMD: Neovascular Age-related Macular Degeneration 
OCT: Optical coherence tomography

PT: previously treated

Q: Quartile

SD: Standard deviation

TAE: Treat-and-Extend

TN: Treatment-naïve

VA: Visual acuity

VEGF: Vascular endothelial growth factor

\section{Declarations}

Ethics approval and consent to participate: The local Ethics Committee approved this study for Clinical Research (UASP, Hospital Clinic de Barcelona, Barcelona, Spain; HCB/2018/0123). Written informed consent was obtained from all patients.

Availability of data and materials: The datasets analysed during the current study are available from the corresponding author on reasonable request.

Competing interests: Gillies and Barthelmes are inventors of the software used to collect the data for this analysis. Zarranz-Ventura is a consultant for Novartis and Bayer, and a grant holder from Novartis.

Funding: The Fight Retinal Blindness! Project is supported by a grant from the Macular Disease Foundation Australia and unrestricted educational grants from Bayer and Novartis.

Authors' contributions: APC collected and interpreted data and wrote the manuscript. MFR and RPCM collected data and edited the manuscript. VN performed the statistical analysis. DB and MCG are inventors of the software and edited the manuscript. JZV wrote and edited the manuscript, is the main director of this study and the national coordinator of the FRB project Spain. All authors read and approved the final manuscript.

Acknowledgements: The authors would like to thank Sarah Steinmann for the web-based support with the FRB platform.

\section{References}

1. CATT Research Group. Martin DF, Maguire MG, Ying GS, Grunwald JE, Fine SL, Jaffe GJ. Ranibizumab and bevacizumab for neovascular age-related macular degeneration. $\mathrm{N}$ Engl $\mathrm{J}$ Med. 
2011 May 19;364(20):1897 - 908.

2. Heier JS, Brown DM, Chong V, Korobelnik JF, Kaiser PK, Nguyen QD, Kirchhof B, Ho A, Ogura Y, Yancopoulos GD, Stahl N, Vitti R, Berliner AJ, Soo Y, Anderesi M, Groetzbach G, Sommerauer B, Sandbrink R, Simader C, Schmidt-Erfurth U; VIEW 1 and VIEW 2 Study Groups. Intravitreal aflibercept (VEGF trap-eye) in wet age-related macular degeneration. Ophthalmology. 2012 Dec;119(12):253748.

3. Abedi F, Wickremasinghe S, Islam AF, Inglis KM, Guymer RH. Anti-VEGF treatment in neovascular agerelated macular degeneration: a treat-and-extend protocol over 2 years. Retina. 2014 Aug;34(8):1531-8.

4. Mehta H, Tufail A, Daien V, Lee AY, Nguyen V, Ozturk M, Barthelmes D, Gillies MC. Real-world outcomes in patients with neovascular age-related macular degeneration treated with intravitreal vascular endothelial growth factor inhibitors. Prog Retin Eye Res. 2018 Jul;65:127-146.

5. Gillies MC, Walton R, Liong J, Arnold JJ, McAllister I, Morlet N, Hunyor A, Guymer R, Keeffe J, Essex R, Herrera-Bond A, Glastonbury B, Simpson JM, Barthelmes D. Efficient capture of high-quality data on outcomes of treatment for macular diseases: the fight retinal blindness! Project. Retina. 2014 Jan;34(1):188-95.

6. Gillies MC, Walton RJ, Arnold JJ, McAllister IL, Simpson JM, Hunyor AP, Guymer R, Essex RW, Morlet $\mathrm{N}$, Barthelmes D. Comparison of outcomes from a phase 3 study of age-related macular degeneration with a matched, observational cohort. Ophthalmology. 2014 Mar;121(3):676-81.

7. Barthelmes D, Campain A, Nguyen P, Arnold JJ, McAllister IL, Simpson JM, Hunyor AP, Guymer R, Essex RW, Morlet N, Gillies MC; Fight Retinal Blindness! Project Investigators. Effects of switching from ranibizumab to aflibercept in eyes with exudative age-related macular degeneration. $\mathrm{Br} \mathrm{J}$ Ophthalmol. 2016 Dec;100(12):1640-1645.

8. Arnold JJ, Campain A, Barthelmes D, Simpson JM, Guymer RH, Hunyor AP, McAllister IL, Essex RW, Morlet N, Gillies MC; Fight Retinal Blindness Study Group. Two-year outcomes of "treat and extend" intravitreal therapy for neovascular age-related macular degeneration. Ophthalmology. 2015 Jun;122(6):1212-9.

9. Gillies MC, Campain A, Barthelmes D, Simpson JM, Arnold JJ, Guymer RH, McAllister IL, Essex RW, Morlet N, Hunyor AP; Fight Retinal Blindness Study Group. Long-Term Outcomes of Treatment of Neovascular Age-Related Macular Degeneration: Data from an Observational Study. Ophthalmology. 2015 Sep;122(9):1837-45.

10. Nguyen V, Daien V, Guymer R, Young S, Hunyor A, Fraser-Bell S, Hunt A, Gillies MC, Barthelmes D; Fight Retinal Blindness! Study Group. Projection of Long-Term Visual Acuity Outcomes Based on Initial Treatment Response in Neovascular Age-Related Macular Degeneration. Ophthalmology. 2019 Jan;126(1):64-74.

11. Warwick AN, Leaver HH, Lotery AJ, Goverdhan SV. Fixed bimonthly aflibercept in naïve and switched neovascular age-related macular degeneration patients: one year outcomes. Int J Ophthalmol. 2016 Aug 18;9(8):1156-62. 
12. Barthelmes D, Nguyen V, Daien V, Campain A, Walton R, Guymer R, Morlet N, Hunyor AP, Essex RW, Arnold JJ, Gillies MC; Fight Retinal Blindness Study Group. Two year outcomes of "treat and extend" intravitreal therapy using aflibercept preferentially for neovascular age-related macular degeneration. Retina. 2018 Jan;38(1):20-28.

13. Carrasco J, Pietsch GA, Nicolas MP, Koerber C, Bennison C, Yoon J. Real-World Effectiveness and Real-World Cost-Effectiveness of Intravitreal Aflibercept and Intravitreal Ranibizumab in Neovascular Age-Related Macular Degeneration: Systematic Review and Meta-Analysis of Real-World Studies. Adv Ther. 2020 Jan;37(1):300-315.

14. Casaroli-Marano R, Gallego-Pinazo R, Fernández-Blanco CT, Figueroa MS, Pina Marín B, FernándezBaca Vaca G, Piñero-Bustamante A, Donate López J, García-Arumí J, Farrés Martí J. Age-Related Macular Degeneration: Clinical Findings following Treatment with Antiangiogenic Drugs. J Ophthalmol. 2014;2014:346360.

15. Rudnicka AR, Jarrar Z, Wormald R, Cook DG, Fletcher A, Owen CG. Age and gender variations in agerelated macular degeneration prevalence in populations of European ancestry: a meta-analysis. Ophthalmology. 2012 Mar;119(3):571-80.

16. Writing Committee for the UK Age-Related Macular Degeneration EMR Users Group. The neovascular age-related macular degeneration database: multicenter study of 92976 ranibizumab injections: report 1: visual acuity. Ophthalmology. 2014 May;121(5):1092-101.

17. Zarranz-Ventura J, Liew G, Johnston RL, Xing W, Akerele T, McKibbin M, Downey L, Natha S, Chakravarthy U, Bailey C, Khan R, Antcliff R, Armstrong S, Varma A, Kumar V, Tsaloumas M, Mandal K, Bunce C, Tufail A; United Kingdom Age-Related Macular Degeneration Electronic Medical Records Users Group. The neovascular age-related macular degeneration database: report 2: incidence, management, and visual outcomes of second treated eyes. Ophthalmology. 2014 Oct;121(10):196675.

18. Almuhtaseb H, Johnston RL, Talks JS, Lotery AJ. Second-year visual acuity outcomes of nAMD patients treated with aflibercept: data analysis from the UK Aflibercept Users Group. Eye (Lond). 2017 Nov;31(11):1582-1588.

19. Rofagha S, Bhisitkul RB, Boyer DS, Sadda SR, Zhang K; SEVEN-UP Study Group. Seven-year outcomes in ranibizumab-treated patients in ANCHOR, MARINA, and HORIZON: a multicenter cohort study (SEVEN-UP). Ophthalmology. 2013 Nov;120(11):2292-9.

20. CATT Research Group, Martin DF, Maguire MG, Ying GS, Grunwald JE, Fine SL, Jaffe GJ. Ranibizumab and bevacizumab for neovascular age-related macular degeneration. N Engl J Med. 2011 May 19;364(20):1897 - 908.

21. Gemenetzi M, Patel PJ. A Systematic Review of the Treat and Extend Treatment Regimen with AntiVEGF Agents for Neovascular Age-Related Macular Degeneration. Ophthalmol Ther. 2017 Jun;6(1):79-92.

\section{Figures}




\section{Visual Outcomes at 24 Months}

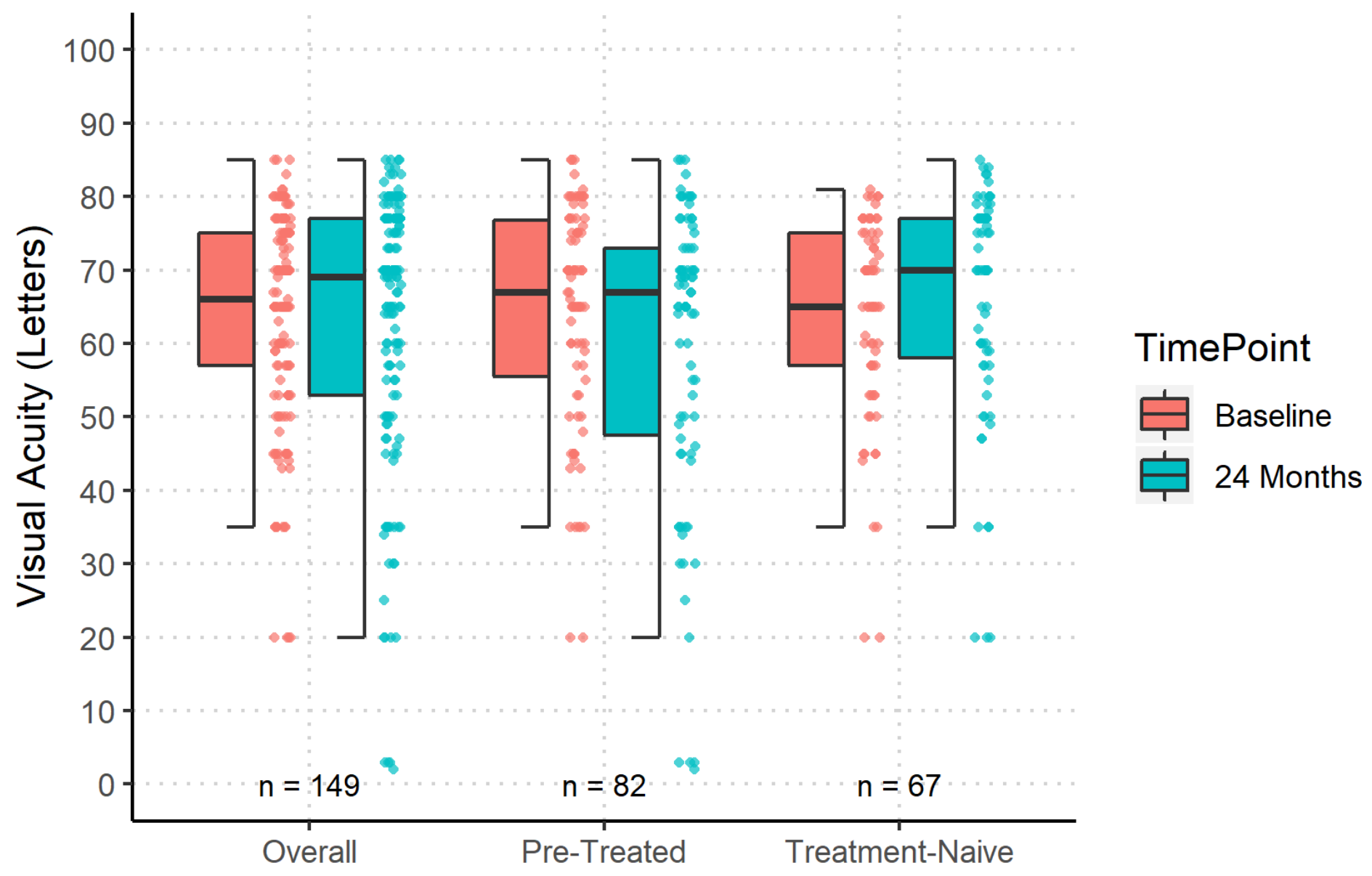

Figure 1

Hybrid boxplot of visual outcomes at 24 months for all 24-month completers (overall), treatment-naïve eyes, and pre-treated eyes. The whiskers represent the 25th and 75th quartiles plus or minus the interquartile range. Each dot represents an individual eye. 